\title{
Twitter as Safe Space for Self-Disclosure among Malaysian LGBTQ Youths
}

\author{
KHADIJAH MOHAMAD TUAH \\ UMMU SYAFIQAH MAZLAN \\ Universiti Malaysia Sarawak
}

\begin{abstract}
Majority of Lesbian, Gay, Bisexual, Transgender and Queer (LGBTQ) youths in Malaysia are not able to express their sexual orientation in real life due to fear of threats and backlash from society. Thus, they turn to social media like Twitter to share their true selves and sexualities. Twitter plays an important role in helping the LGBTQ youths to reveal their true selves and finding a sense of belonging to a community that supports and encourages them and in a country like Malaysia, that is important to their mental well-being. Ten participants from the LGBTQ community gave their consent to be interviewed. This study focuses on the concept of self-disclosure between the participants and their Twitter followers. The results are organized around three primary themes. 1) The motivation includes knowledge, private life, self-acceptance, and movement and clique. 2) Reciprocity in self-disclosure from both the giving and receiving end which can be positive or negative. Under the giving end, recognition is positive whereas exclusion is negative and under the receiving end, acceptance is positive while dismissal is negative. 3) Consequences of disclosure in the forms of income that is internal gain and outcome, the external gain. It is found that the participants' actual intentions of selfdisclosure are self-acceptance and self-actualization. They use Twitter as it is seen as a private space where they can be themselves and be safe, supporting the notion of Twitter as a safe space for LGBTQ youths.
\end{abstract}

Keywords: LGBTQ, Twitter, self-disclosure, safe space, youth.

\section{INTRODUCTION}

Lesbian, Gay, Bisexual, Transgender and Queer (LGBTQ) is a sensitive topic in Malaysia regardless of religion, culture and belief. According to Mohd Afiq (2015), the Malaysian community still believe LGBTQ is a bad influence and spreads like a virus. Azwan Ismail in 2010 received a huge backlash from Malaysians after exposing his sexuality on Youtube (The Star Online, 2010). He even received death threats as a result of his coming out. Thus, coming out is not an option for most LGBTQs in the conservative society. Malaysia's Tourism Minister, Mohamaddin Ketapi, even denied the existence of gay people in Malaysia, telling the German reporters that "I don't think we have anything like that in our country" (McKirdy, 2019).

Due to the possibility of threats and backlash as well as the denial of their existence, LGBTQ youths turn to social media to explore related matters, find a sense of belonging and socialize (Jenzen \& Karl, 2014) and this study focuses on Twitter as a safe space for LGBTQ youths to disclose their identities and sexualities with the knowledge that there are accepting communities online to support them. Therefore, it is important to identify their motivation for self-disclosure on Twitter as well as recognize the reciprocity and consequences gained in the process.

The study on LGBTQ youths is important to understand what they are trying to portray to the society, that is their positive selves, as opposed to what has been positioned upon them, such as promoting LGBTQ lifestyle (Mohd Anwar, 2018), by society with little or zero knowledge about what LGBTQ is about. The youths need healthy and thoughtful discourses 
not just among themselves but also their allies and oppositions and this can occur on an online platform such as Twitter.

\section{LGBTQ Youths and Social Media}

The social media of choice among Malaysian youths is Facebook and it has been shown to have a huge impact on them (Saodah, Syed Arabi \& Norealyna, 2012; Faradillah lqmar Omar, Nor Azlili Hassan, Iza Sharina Sallehuddin \& Nor Hafizah Abdullah, 2016) with some youths spending more than four hours daily on Facebook (Joo \& Teng, 2017). Facebook is used to communicate with friends and family, to get acquainted with new friends, as well as a source of entertainment and news. However, neither studies mention expressing one's sexual orientation and this is one of the reasons social media like Twitter is a preference among LGBTQ youths in Malaysia. Facebook is for family members and friends and most of them do not have a Twitter account, especially their parents.

In a conservative country like Malaysia, LGBTQ youths normally choose to conform to the norms of society in real life and turning to social media to express their true selves. Jenzen and Karl (2014) implied that LGBTQ youths have limited use of public spaces, are being limited with their expression of identity and constrained in exploring their sexual identities especially in public places. These youths turn to social media to find the space that is lacking in real life as a solution to fulfil their specific needs. Paradis (2016) explained that the top two most necessitated environments are inclusive space and socializing space for queer people. These youths not only consume the information they found online but they are also content providers, sharing their knowledge and information with other youths.

LGBTQ youths are more likely to participate in LGBTQ communities online as they feel safer and more supported and they normally engage in activities like seeking information, finding support and looking for resources (Mclnroy et al., 2019). Yusop and Sumari's (2013) study on Malaysian youth and social media found that they use social media to share information and to search for educational materials.

Social media as identified in a study by Chong, Zhang, Mak and Pang (2015) is important to the LGBTQ youths as it offers group membership by means of community surveillance, identity expression, and emotional support. However, some youths are careful of what they share online especially regarding their sexuality as found in Martin's (2016) study where participants are careful regarding whom and how much they choose to share online and some even go to certain extents to conceal their real identities online.

\section{LGBTQ Youths and Safe Space}

The concept of safe space used in this study refers to the earlier definition of safe space that is used to describe "physical meeting places where like-minded people could meet and share their experiences in a safe environment" (Flensner \& der Lippe, 2019) especially for women and LGBTQ movement. Here safe space is used to relate to the potentially safe environment offered by Twitter for the LGBTQ youths in Malaysia.

Creating a safe space is a way of implementing social justice that not only recognizes and emphasizes but also encourages social difference (The Roestone Collective, 2014). LGBTQ youths see themselves differently from heterosexual youths and they need a safe space where they are recognized for their difference. Brownlie (2018) proposed that the idea of a safe space, including safe space online, is important in the sharing of emotion online. In this study, Twitter is seen as a safe space for sharing or disclosing sexual orientation online. 
Twitter offers the LGBTQs "a space to share their offline lives and offline live experiences" online (Maliepaard, 2017) with the LGBTQ community as they regarded online spaces as safe spaces that offer them safety in terms of support and acceptance. Lucero's (2017) study on whether social media provide a safe space for LGBTQ youths to express and explore issues of sexuality and gender found the result to be positive as they feel safe and comfortable using social media to explore and express their gender and sexual identity.

Noor Hafizah and Norsaleha (2016) still declared LGBTQ as a mental illness for going against nature even though the American Psychiatric Association has removed homosexuality from the list of mental illness since 1973 (Kozuch, 2017). LGBTQ itself is not a mental illness but some of the LGBTQs do suffer from mental illness such as depression and anxiety for having to conceal their true selves and by being marginalized, discriminated against, prejudiced, and stigmatized (Zazzarino \& Bridges, 2019) as well as early negative experiences (Rivers et al., 2018).

Thus, Twitter plays an important role in helping the LGBTQ youths to reveal their true selves and finding a sense of belonging to a community that supports and encourages them and in a country like Malaysia, that is important to their mental well-being.

\section{Self-Disclosure among LGBTQ Youths}

This study focuses on the concept of self-disclosure between the participants and their Twitter followers. It is a process whereby individuals open up about their personal selves and theoretically, the end process is to achieve a stable exchange of communication (West \& Turner, 2014).

Self-disclosure, as mentioned by Green, Bobrowicz and Ang (2015) vary in its level of intimacy. LGBTQ youths are careful in disclosing their sexual orientation where they perceive it will result in a negative reaction. Disclosure on sexual orientation by LGBTQs in social media has a different "degree of outness" that ranges from mostly in the closet, peeking out, partially out, to out (Dhoest \& Szulc, 2016). This is the reason the terms closeted, half-closeted and out are common among the LGBTQ community.

Despite the potential backlash, these youths chose to disclose their sexual orientation online as it improves interpersonal relationships, enhance their mental and physical health, and they also hope it will change society's attitudes (Herek as cited in Green et al., 2015). Mental health concern is closely associated with LGBTQs and by disclosing online and receiving support from the community help them deal with this. This is one of the main reasons for the youths to disclose their gender identity and sexual orientation as coming out online whether fully or half has been proven to benefit mental health and increase access to social support (Blackwell et al., 2016). This is further supported by Soohinda, Jaggi, Sampath and Dutta (2018) in their study on sexual orientation, relationships pattern, social connectedness, disclosure, and self-esteem in Indian men who use an online gay dating website. They found that self-disclosure on sexual orientation is an important aspect of LGBTQ's identification and social acceptance.

It is important for LGBTQs to be visible and engage in the "politics of visibility" as being visible is associated with making a political statement about one's true identity and sexuality and is a practice that is encouraged in the broader LGBTQ politics (Hanckel et al., 2019). However, not everyone can afford to be visible about their sexuality in real life and this results in them turning to an anonymous social media platform like Twitter. 
Twitter users can choose their own tweet handle or Twitter handle that is their username and some users chose not to use their real names. Even though they reveal their sexuality on Twitter, not everyone knows who they really are. This is supported by Dhoest and Szulc (2016) that even though LGBTQs tend to be more open about their gender identity or sexual orientation on Twitter, it does not mean that they always clearly identify themselves on that platform. LGBTQs who feel the need to conceal their real identities normally turn to more anonymous online spaces such as Twitter where they can freely tweet LGBTQ content and even subscribe to or follow LGBTQ-themed accounts (Duguay, 2014).

\section{METHODOLOGY}

For this study, the target population is Malaysian LGBTQ youths who use Twitter to express their sexuality. Thus, participants need to be Malaysian, conform to the LGBTQ community, Twitter user and express their sexual orientation openly on Twitter. According to the Youth Societies and Youth Development Act (Amendment) 2019 (Act 668), youth is defined as a person between the ages of 15 and 30 (Arfa Yunus, 2019). However, in some states in Malaysia, the age range is maintained between 15 and 40 years old. Ten participants aged between 21 to 34 years old from various gender identity and sexual orientation agreed to be part of this study.

As the study encompasses LGBTQ youths, the researchers tried to recruit two participants for each definition. Lesbian is defined as a female who is sexually attracted to other females; gay is for a male who is sexually attracted to other males; bisexuals refer to those who are sexually attracted to both sexes; transgender people are those with gender identities that are different from their assigned sexes; whereas queer is whose gender, gender expression and/or sexuality does not conform to dominant expectations and they can fall anywhere along the spectrum (LGBTQIA Resource Center, 2019). The Queer theory believes that nothing within one's identity is fixed and that gender is a performance and thus, people can change (Gauntlett, 2008).

Purposive sampling was used where participants were selected because of their sexual orientation and self-disclosure on Twitter. Data collection was conducted through interview sessions with the participants using open-ended questions. The interviews were conducted in English and all quotes are verbatim transcriptions of the interviews. This is a qualitative study and data collected will be analyzed using thematic analysis. Questions for the interview were constructed based on the objectives of the study, which are 1) What is the motivation for them to self-disclose on Twitter, 2) What are the reactions of others and their own reactions towards those reactions during their process of self-disclosure, and 3) What are the consequences or significance they gained by their self-disclosure. Other questions include demographic and personal information with regards to LGBTQ matters.

Participants' consent and confidentiality is very important in this study due to the subject being studied. Participants needed to voluntarily participate in this study and they need to be comfortable in expressing themselves not just through mediated communication but also face-to-face communication as they will be interviewed. Permission was also obtained to view their tweets. Data from the interview sessions will be transcribed and analyzed into themes.

\section{RESULTS AND DISCUSSION}

The results are organized around three primary themes. 1) The motivation includes knowledge, private life, self-acceptance, and movement and clique. 2) Reciprocity in self- 
disclosure from both the giving and receiving end which can be positive or negative. Under the giving end, recognition is positive whereas exclusion is negative and under the receiving end, acceptance is positive while dismissal is negative. 3 ) Consequences of disclosure in the forms of income that is internal gain and outcome, the external gain.

Participants are labelled by numbers as a matter of confidentiality. Based on Table 1 below, the participants consist of three males with male gender identity and whose sexual orientation are homosexuals (gays). Only one female with female gender identity identified as a lesbian while the other female lesbian is a butch. Two females are bisexuals while another female is pansexual. It is interesting to note that one participant is a transwoman whose sexual orientation is lesbian and another is a transman whose sexual orientation is pansexual. This group of participants is a reflection of the LGBTQ community as it includes gays, lesbians, bisexuals and pansexuals (sexual orientation) and transman and transwoman (gender identity).

In terms of education, seven participants are bachelor degree holders while the other three are diploma holders. All participants came to realize their sexual orientation during adolescents.

Looking at the participants' status, six of them are half-closeted and only four have totally come out. Those who are half-closeted came out to trusted friends and those on Twitter. In the case of transman and transwoman, it is impossible for them not to come out where gender identity is concerned but as for sexual orientation, that is known only to a certain group of people.

Table 1: Demographic data of participants

\begin{tabular}{llllll}
\hline & Age & Assigned Sex & Gender Identity & $\begin{array}{l}\text { Sexual } \\
\text { Orientation }\end{array}$ & Status \\
\hline P1 & 22 & Female & Butch & Lesbian & Half-closeted \\
P2 & 24 & Female & Transman & Pansexual & Came out \\
P3 & 21 & Male & Male & Homosexual & Came out \\
P4 & 34 & Male & Transwoman & Lesbian & Came out \\
P5 & 27 & Female & Female & Pansexual & Half-closeted \\
P6 & 22 & Female & Female & Bisexual & Half-closeted \\
P7 & 23 & Female & Female & Bisexual & Came out \\
P8 & 21 & Male & Male & Homosexual & Half-closeted \\
P9 & 20 & Female & Female & Lesbian & Half-closeted \\
P10 & 25 & Male & Male & Homosexual & Half-closeted \\
\hline
\end{tabular}

\section{Motivation of Self-Disclosure}

The question asked was "What was the motivation for you to express your sexuality through Twitter?" Four factors are identified based on answers given where most participants are motivated by knowledge, followed by private life, self-acceptance, and movement and clique.

\section{a. Knowledge}

Gaining and disseminating knowledge about LGBTQ is the highest motivation factor for selfdisclosure as they get to share information and educate themselves to better understand the LGBTQ community. P5 learned "the important information, categories, definitions, culture of LGBTQ the hard way". She wanted this information to be disseminated so society can understand and will not be misinformed as this contributes to the negative image of LGBTQ. 
P2 said, "I want to educate myself and others about sexualities other than bisexuals and homosexuals." She wanted to focus on other sexualities such as pansexuals, asexuals, and demisexuals, which the community is unfamiliar with. P4 and P9 tweeted about general issues concerning LGBTQ but for P4, a transwoman, her main focus issues "that affect lesbian and transgender." $\mathrm{P} 10$ 's focus is more on "sharing ideas and initiating constructive discussion" including positive discourse on current issues affecting the LGBTQ community in Malaysia.

\section{b. $\quad$ Private Life}

The second most talked about is their private lives as this is the platform for them to freely express their personal lives including their partners, lifestyles and freedom of speech. P3 believed there is nothing to hide about his sexuality and he expressed this by saying what he wanted. P9 is comfortable with Twitter due to the privacy it provides. Her Twitter account is set to private and having a smaller circle of friends and followers made her feel comfortable talking about her partner. As for P10, his main motivation is because his family is not on Twitter and this gives him a safe space to be more outspoken about his sexuality.

\section{c. Self-Acceptance}

Most of the participants' motivation for self-disclosure on Twitter is the opportunity to be their true selves. "Being myself" indicates how they embrace their sexuality without the fear of judgement from society. The participants also believe that "coming out" is a way for them to accept who they really are and Twitter is seen as a safe space. Six of the ten participants are "half-closeted" which means they only came out to selected people, and this is done through Twitter.

P6 was motivated to disclose her sexuality when she realized her circle of friends is very supportive of her being a bisexual. Thus, her "coming out" on Twitter and being able to talk about her sexuality openly is the "most significant part of myself." According to her, "I feel more confident of being myself and not just hide the most significant part of myself just because I was not identified as straight...embracing who I really am is very important." P7 came out to her online friends because she was heavily involved with civil society and likeminded people. She believed if she did not disclose her bisexuality, her sexual orientation will often be questioned and she will have to repeatedly explain that she is a bisexual. P8 chose to self-disclose to his Twitter friends "as a means of accepting and embracing my true self, knowing they won't judge or view me differently."

\section{d. $\quad$ Movement and Clique}

Another motivation for self-disclosure on Twitter is the movement and creating LGBTQfriendly cliques. The movement here refers to an online group with the same interest in fighting bigotry especially towards the LGBTQ community and spreading awareness. They do this by tweeting information and those who are more open will directly reply to prejudiced tweets and they are normally supported by their friends. Some participants gain new LGBTQfriendly cliques while some are there for comfort and sharing the same interests and experiences in being part of the community.

P5 admitted she disclosed her sexuality on Twitter because she wants to fight the discrimination she feels the community has suffered. She insisted that "LGBTQ often received death threats and shot down for just being who they are, we need the public to know that we are humans, that their negative ideas might be wrong, that the whole surface of being LGBTQ is love, and no one can take that from us." 
P10's motivation was "to get more connections with people like me" which indicates he wanted to find friends and acquaintances who are queer like himself. This suggests that having a movement and finding groups of similar interests give the participants motivation for self-disclosure on Twitter.

\section{Reciprocity in Self-Disclosure}

Two questions were asked to find out reciprocity in the process of self-disclosure, "What are the reactions you get from other people on your self-disclosure?" and "What is your own reaction towards others' reactions on your self-disclosure?" in the spectrum of giving and take, it is found that participants received both positive and negative reactions and they also reacted on those reactions positively and negatively. On the receiving end, the analysis will be drawn into acceptance (positive reaction) and dismissal (negative reaction). On the giving end, analysis will be drawn into recognition (positive act) and exclusion (negative act).

\section{a. Receiving End: Acceptance}

Receiving end is based on the question "What are the reactions you get from other people on your self-disclosure?". Positive reaction or acceptance mostly comes from the LGBTQ community and friends who are understanding and are allied with the community. The participants gain support, reassurance and encouragement.

P2, a transman, received reassurances such as compliments on him being able to talk openly about his transitional journey. Some even asked him for advice and "want to be as comfortable as me." According to P6, she received good treatment from her circle of friends and this encouraged her to be herself more. P7 revealed she has difficulties finding supportive friends in real life but "Twitter community is surprisingly supportive and loving enough to have me around." Whereas for $\mathrm{P} 10$, he said more people are attracted to him as they felt that "they are not alone."

These positive responses came mostly from understanding close friends, allies of the LGBTQ community and the LGBTQ community members themselves. P1 and P9 told the story of their coming out to their existing friends and were received neutrally where their friends just said "okay". For them to receive a positive response from those on Twitter is revealing to them and contributes to their understanding of themselves and the community.

\section{b. $\quad$ Receiving End: Dismissal}

Negative reactions or dismissal are usually received from existing or old friends who knew before their coming out and also from society who are prejudice towards the LGBTQ community. P1 shared how her old friends used to criticize her behind her back but would say and do nothing in front of her. P4's friends unfriended her during her pre-transitioned. P5 who is considered as vocal in expressing her "liberating thoughts" said it is difficult for those living in a conservative society to accept LGBTQ because they have been told that "this" is wrong their entire life. Nevertheless, she thinks progress is vital and she will not stop being vocal on Twitter.

P6 mentioned she received threats and was judged poorly because she came out on Twitter, "I might be an apostate, some say that I am too secular." P9 had friends who threatened her if she does not want to "change and go back to the right path." This suggests that the participants also receive negative reactions which are normally harsh not only from society but also from those whom they considered friends. 


\section{c. Giving End: Recognition}

The question "What is your own reaction towards others' reactions on your self-disclosure?" was asked to find out the participants' own reactions towards the positive and negative reactions of others. In terms of recognition, the participants reacted positively towards what they gained. Most of them recognized that the treatment they received is what they have expected when they disclose their sexuality.

Reciprocating the positive acceptance they received, the participants also contribute to the "support system" within the community. For P2, those who seek advice from him in transitioning, he will support them. P9 said she will lend her support to those who wish to come out on social media and she will "encourage and motivate them."

For the dismissal that they gained, their positive reaction is to understand why they were rejected. They educate themselves on the reasons for the conservative mindset and attitudes of the society towards the LGBTQ community and find ways to correct the misleading views towards the community. P5 explained that she had to educate herself with facts because intelligent arguments need facts when encountering the dismissal from others. P7 believed that "everyone is entitled to a wrong opinion' hence the society has their own perception and thoughts. P10 said that "proud and out is okay but proud and loud is not okay", explaining that being too loud in one's belief is not acceptable.

\section{d. Receiving End: Exclusion}

Several dismissals are too harsh that the only way for the participants to react towards them is negatively, or known as exclusion where they either exclude or ignore the reaction. Most of the participants chose to avoid those with harsh negative reactions either by blocking or muting them. Twitter offers those options where users can block or mute undesired accounts.

P3 commented that "there is no point in fighting people like that, I basically block them." As for P6, she would "ignore their existence" as she believed it will distort her growth and potential as a human being. Some participants just "let them be" as P4 noted that "they are not contributing in my life in any tangible ways anyway." The participants' reactions towards others' reactions can be both positive and negative depending on the harshness of the treatment they received. Reciprocity is part of the process of self-disclosure and positive reactions will receive positive feedback.

\section{Consequences of Disclosure}

The third objective of the study is to understand the consequences gained by the participants and two questions were asked, "What are the incomes you get in the process of selfdisclosure?" and "What are the outcomes you get in the process of self-disclosure?" Income in this context refers to the internal and intangible rewards participants gained from the process. The outcome is the external and tangible rewards they gained.

\section{Income}

Three major gains are identified based on the participants' responses which are selfactualization, esteem and knowledge.

\section{a. Self-Actualization}

Throughout the process of disclosure, the participants' most frequent answers are related to self-actualization. In Maslow's hierarchy of needs, self-actualization is the highest level in the pyramid where there are several characteristics for people to achieve. Some of the 
characteristics that are parallel to the participants' answers are acceptance of themselves and others, appreciation of life, and guidance from own inner goals and values.

P1 professed she felt comfortable with herself whenever she disclosed her true self on Twitter. P3 claimed "self-understanding" while P4 said she has a whole new perception about her faith. Meanwhile, P5 started to understand the community as a whole after he disclosed himself.

\section{b. $\quad$ Esteem}

Esteem is the next frequent answer from the participants. Self-actualization requires people to be in a state of their best version of themselves and esteem is the need to be fulfilled before they reach the state. The needs include being confident, masterful and feeling worthy of themselves. P1, P4 and P6 agreed that the process of disclosing themselves have boosted their confidence level, specifically in opening up to the community. P10 declared that because of disclosure, "I am extra firm with my life principle."

\section{c. Knowledge}

The final income gained by the participants is knowledge. Most of the knowledge gained is LGBTQ related. This is due to the fact that knowledge on LGBTQ cannot be obtained through the mainstream medium as it is regarded as taboo by the Malaysian society. Thus, Twitter is an alternative platform for them to obtain knowledge.

According to P2, he had gained more knowledge about transgender, locally and internationally through Twitter and his Twitter followers. P4 said she gained "more knowledge about myself and the community." As for P5, she not only gained but also shared her knowledge and experiences about being in the local LGBTQ community with others.

\section{Outcome}

Responses gathered from the participants about their tangible gains through the process of the disclosure can be categorized into connections, compliments and acknowledgement.

\section{a. Connections}

Connections are people from the community that they gained trust with, where they became friends or acquaintances. Majority of the participants mentioned they formed new friendships either just online or offline where they meet up and become friends in real life. However, in some cases, they also lost friends in their process of self-disclosure. P3 and P4 admitted they gained new friends and a new circle of friends within the LGBTQ community. As for P5 and P7, they gained new friends who are very supportive of who they are and they have also lost some friends who cannot accept them after disclosing themselves being part of the LGBTQ community.

\section{b. Compliments and Acknowledgement}

This is when the participants are acknowledged by the LGBTQ community, both the inner and outer circle. Compliments are usually given for their bravery in stepping out of their comfort zone and being open about their sexuality.

P2 was given acknowledgement by the LGBTQ community especially the transgender community because prior to him coming out, they thought he was just a cis ally man. He also received compliments for being open to it. P5 was acknowledged for being vocal on Twitter and had received several invitations to write about LGBTQ issues. As for P6, she was asked 
about her opinion on coming out and the LGBTQ community and some came out after she responded. She felt responsible for their coming out being proud of themselves.

While not all participants are like P5 in being vocal about LGBTQ issues and can be categorized as an activist, most of the participants do seek to inform or share information in their own ways and this can be regarded as "everyday activism" (Hanckel et al., 2019).

\section{CONCLUSION}

The LGBTQ community is regarded as an obscene "movement" in Malaysia due to the negative perception of society. They believe that LGBTQ is caused by the liberalization that comes from promoting freedom of rights which is beyond the local belief, religion and norms (Mohd Afiq, 2015). As claimed by Kamal Azmi, Mastura and Ain Balkis (2015), the availability and openness of social media is an option for LGBTQs to promote their agenda and build their network. This differs from the participants' actual intentions of self-disclosure which are selfacceptance and self-actualization. None of the participants wish to influence others to become part of the LGBTQ community nor do they wish to promote their LGBTQ agenda or lifestyle to the public.

Malaysian society is also of the opinion that the LGBTQ community are abusing social media to jeopardize society (Mohd Afiq, 2015). However, Nurul Jannah, Mutia Sobihah, Lukman, Normala and Azlini (2017) offered a different perspective where they stated that lesbians in Malaysia gravitate towards social media to gain emotional support and guidance as well as to have a voice without any prejudice from society. Although their study specifically focuses on lesbians, the motive is applicable to the rest of the LGBTQs. This is concurrent with findings by Paradis (2016) where LGBTQ youth's main use of social media is to "socialize and to feel a sense of belonging."

As proven in the motivation analysis, the main reason the participants disclose their sexuality on Twitter is to seek knowledge, which is a positive thing. Apart from that, they use Twitter as it is seen as a private space where they can be themselves and be safe, supporting the notion of Twitter as a safe space for LGBTQ youths. Twitter has helped these youths in disseminating their neglected and misunderstood voices.

It is also important to acknowledge the diverse gender identities and sexualities in the LGBTQ spectrum and they are not merely male, female, and transgender or lesbians, gays and bisexuals but there is a myriad of other gender identities and sexualities. Society tends to assume transwomen will be attracted to cis males (males who are assigned males at birth) but as found in the study, they can also be lesbians.

This study, however, does not represent the whole Malaysian LGBTQ youths on Twitter and it is recommended for future research to include more participants, not just youths but activists as well and data mining on tweet contents and themes.

\section{BIODATA}

Khadijah Mohamad Tuah is a senior lecturer at the Faculty of Language and Communication, Universiti Malaysia Sarawak. Email: mtejah@unimas.my

Ummu Syafiqah Mazlan is a final year student at the Faculty of Social Sciences and Humanities, Universiti Malaysia Sarawak at the time of data collection. Email: ummumazlan96@gmail.com 


\section{REFERENCES}

Arfa Yunus Esther Landau. (2019). 'Youth' now defined as those between 15 and 30. The New Straits Times. Retrieved from https://www.nst.com.my/news/nation/2019/07/501288/youth-now-defined-thosebetween-15-and-30

Blackwell, L., Hardy, J., Ammari, T., Veinot, T., Lampe, C., \& S. Schoenebeck. (2016). LGBT parents and social media: Advocacy, privacy, and disclosure during shifting social movements. Proceedings of the 34th Annual ACM Conference on Human Factors in Computing Systems (CHI '16), New York: ACM Press.

Brownlie, J. (2018). Looking out for each other online: Digital outreach, emotional surveillance and safe(r) spaces. Emotion, Space and Society, 27, 60-67.

Chong, E. S., Zhang, Y., Mak, W. W., \& Pang, I. H. (2015). Social media as social capital of LGB individuals in Hong Kong: Its relations with group membership, stigma, and mental well-being. American Journal of Community Psychology, 55(1-2), 228-238.

Dhoest, A., \& Szulc, L. (2016). Navigating online selves: Social, cultural, and material contexts of social media use by diasporic gay men. Social Media + Society, October-December, 1-10.

Duguay, S. (2014). 'He has a way gayer Facebook than I do': Investigating sexual identity disclosure and context collapse on a social networking site. New Media and Society. doi: $10.1177 / 1461444814549930$

Faradillah Iqmar Omar, Nor Azlili Hassan, Iza Sharina Sallehuddin, \& Nor Hafizah Abdullah. (2016). Gen Y: A Study on Social Media Use and Outcomes. Journal of Management \& Muamalah, 6(1), 53-64.

Flensner, K. K., \& der Lippe, M. V. (2019) Being safe from what and safe for whom? A critical discussion of the conceptual metaphor of 'safe space'. Intercultural Education, 30(3), 275-288.

Gauntlett, D. (2008). Media, gender and identity: An introduction, 2nd edition. London, UK: Routledge.

Gay man fears for his life after exposing his sexuality on Net (2010). The Star Online. Retrieved from https://www.thestar.com.my/news/nation/2010/12/23/gay-man-fears-for-hislife-after-exposing-his-sexuality-on-net\#5csSiKqAylKR3Yqy.99

Green, M., Bobrowicz, A., \& Ang, C. S. (2015). The lesbian, gay, bisexual and transgender community online: Discussions of bullying and self-disclosure in YouTube videos. Behaviour \& Information Technology, 1-9.

Hanckel, B., Robards, B., Vivienne, S., Byron, P., \& Churchill, B. (2019). "That's not necessarily for them": LGBTIQ+ young people, social media platform affordances \& identity curation. Media Culture \& Society. doi: 10.1177/0163443719846612

Jenzen, O., \& Karl, I. (2014). Make, share, care: Social media and LGBTQ youth engagement. A Journal of Gender, New Media, and Technology, 5.

Joo, T. M. \& Teng, C. E. (2017). Impacts of social media (Facebook) on human communication and relationships: A view on behavioral change and social unity. International Journal of Knowledge Content Development \& Technology, 7(4), 27-50.

Kamal Azmi Abd. Rahman, Mastura Md. Nizam, \& Ain Balkis Mohd Azam. (2015). Profil masyarakat Melayu Malaysia di media sosial yang mempromosikan LGBT. Paper presented at International Seminar on Media \& Dakwah, Akademi Islam Universiti Malaya, Malaysia. 
Kozuch, E. (2017). \#FlashbackFriday-Today in 1973, the APA Removed Homosexuality From List of Mental Illnesses. Human Rights Campaign. Retrieved from https://www.hrc.org/blog/flashbackfriday-today-in-1973-the-apa-removedhomosexuality-from-list-of-me

Lucero, L. (2017). Safe spaces in online places: Social media and LGBTQ youth. Multicultural Education Review, 9(2), 117-128.

LGBTQIA Resource Center. (2019). Retrieved from https://Igbtqia.ucdavis.edu/educated/glossary

Maliepaard, E. (2017). Bisexual safe space(s) on the internet: Analysis of an online forum for bisexuals. Tijdschrift voor Economische en Sociale Geografie, 108(3), 318-330.

Martin, A. (2016). Perceptions surrounding cyberbullying and self-disclosure among the LGBTQ community: A qualitative approach. Media and Communication Studies Summer Fellows, 5.

McInroy, L. B., McCloskey, R. J., Craig, S. L. \& Eaton, A. D. (2019). LGBTQ+ youths' community engagement and resource seeking online versus offline. Journal of Technology in Human Services, 37(4), 315-333.

McKirdy, E. (2019). There are no gay people in Malaysia says tourism minister. CNN. Retrieved from https://edition.cnn.com/2019/03/07/asia/malaysia-tourism-minister-gaydenial-intl/index.html

Mohd Afiq Aiman Abd Hamid. (2015). The usage of social media in sharing information among LGBT community in Malaysia (Unpublished masters dissertation, Universiti Teknologi Mara, Malaysia).

Mohd Anwar Patho Rohman. (2018). No place for liberalism in the promotion of LGBT lifestyle, says Mujahid. The New Straits Times. Retrieved from https://www.nst.com.my/news/nation/2018/11/435764/no-place-liberalismpromotion-lgbt-lifestyle-says-mujahid

Noor Hafizah Mohd Haridi, \& Norsaleha Mohd Salleh. (2016). Kumpulan lesbian, gay, biseksual dan transgander (LGBT) ancaman terhadap keamanan dan keharmonian beragama di Malaysia. ISLAM RELITAS: Journal of Islamic \& Social Studies, 2(2), 205211.

Nurul Jannah Mohd Juaini, Mutia Sobihah Abd. Halim, Lukman @ Zawawi Mohamad, Normala Riza, \& Azlini Chik (2017). Social media and lesbians in Malaysia. International Journal of Academic Research in Business and Social Sciences, 7(11), 1005-1014.

Paradis, E. (2016). Searching for self and society: Sexual and gender minority youth online. In A. Wilson \& V. Bloomfield (Eds.), LGBTQ voices in education: Changing the culture of schooling (pp. 87-101). New York: Paradigm Publishers.

Rivers, I., Gonzalez, C., Nodin, N., Peel, E. \& Tyler, A. (2018). LGBT people and suicidality in youth: A qualitative study of perceptions of risk and protective circumstances. Social Science \& Medicine, 212, 1-8.

Saodah Wok, Syed Arabi Idid, \& Norealyna Misman. (2012). Social media use for informationsharing activities among youth in Malaysia. Journalism and Mass Communication, 2(11), 1029-1047.

Soohinda, G., Jaggi, P. S., Sampath, H., \& Dutta, S. (2018). Self-reported sexual orientation, relationships pattern, social connectedness, disclosure, and self-esteem in Indian men who use online gay dating website. Open J Psychiatry Allied Sci, 1. 
The Roestone Collective. (2014). Safe space: Towards a reconceptualization. Antipode, 46(5), 1346-1365.

West, R., \& Turner, L. H. (2014). Introducing communication theory : Analysis and application (5th ed.). New York: McGraw-Hill Education.

Yusop, F. D., \& Sumari, M. (2013). The use of social media technologies among Malaysian youth. Procedia - Social and Behavioral Sciences, 103, 1204-1209.

Zazzarino, A., \& Bridges, C. W. (2019). A population at risk: Counseling sexual minorities with a serious mental illness. Journal of Counseling Sexology \& Sexual Wellness: Research, Practice, and Education, 1(1). 